\title{
Patterns of Sexual Behaviour Associated with Repeated Chlamydia Testing and Infection in Men and Women: A Latent Class Analysis
}

\section{Inga Veličko ( $\square$ inga.velicko@ki.se)}

Karolinska Institutet https://orcid.org/0000-0001-7538-2339

\section{Alexander Ploner}

Karolinska Institute Department of Medical Epidemiology and BiostatisticsScience Park: Karolinska Institutet Science Park AB

\section{Lena Marions}

Karolinska Institutet Department of Clinical Science and Education

\section{Pär Sparén}

Karolinska Institute Department of Medical Epidemiology and Biostatistics

\section{Björn Herrmann}

Uppsala University Department of Medical Sciences

\section{Sharon Kühlmann-Berenzon}

Public Health Agency of Sweden: Folkhalsomyndigheten

\section{Research article}

Keywords: Latent class analysis, sexual behaviour patterns, testing for Chlamydia trachomatis, ordered logistic regression, stratified analysis by sex, Sweden

Posted Date: April 1st, 2021

DOl: https://doi.org/10.21203/rs.3.rs-368797/v1

License: (a) (1) This work is licensed under a Creative Commons Attribution 4.0 International License. Read Full License

Version of Record: A version of this preprint was published at BMC Public Health on April 5th, 2022. See the published version at https://doi.org/10.1186/s12889-021-12394-0. 


\section{Abstract}

Background: Adolescents and young adults are at higher risk of acquiring Chlamydia trachomatis infection (chlamydia), so testing is promoted in these populations. Studies have shown that re-testing for chlamydia is common amongst them. We investigated how sexual risk behaviour profiles are associated with repeated testing for chlamydia.

Methods: We used baseline data from a cohort of 2,814 individuals recruited at an urban STI-clinic. We applied latent class (LC) analysis using 9 manifest variables on sexual behaviour and substance use selfreported by the study participants. We fitted ordered logistic regression to investigate the association of LC membership with the outcomes repeated testing during the past 12 months and lifetime repeated testing for chlamydia. Models were fit separately for men and women.

Results: We identified four LCs for men and three LCs for women with increasing gradient of risky sexual behaviour. The two classes with the highest -risk among men were associated with lifetime repeated testing for chlamydia: adjOR $=2.26(95 \% \mathrm{Cl}: 1.50-3.40)$ and adjOR $=3.03(95 \% \mathrm{Cl}: 1.93-4.74)$ as compared with the class with lowest risk. In women, the class with the highest risk was associated with increased odds of repeated lifetime testing (adjOR $=1.85$ (95\% Cl: 1.24-2.76)) and repeated testing during past 12 months (adjOR $=1.72(95 \% \mathrm{Cl}: 1.16-2.54))$. An association with chlamydia positive test at the time of the study and during the participant's lifetime was only found in the male high-risk classes.

Conclusion: Prevention messages with regard to testing for chlamydia after unprotected sexual contact with new/casual partners seem to reach individuals in high-risk behaviour classes who are more likely to test repeatedly. Prevention efforts should involve enhanced targeting and promotion of safe sex.

\section{Background}

Among bacterial sexually transmitted infections (STIs), Chlamydia trachomatis infection (chlamydia) has the highest burden globally [1], with the potential to cause serious reproductive health sequalae, such as pelvic inflammatory disease, ectopic pregnancy, and tubal infertility [2-6]. As chlamydia infection is often asymptomatic [7, 8], control measures are aimed at reducing chlamydia incidence and prevalence, as well as potential complications, through screening (testing), treatment and partner notification [9]. Recommendations for annual chlamydia screening in Europe target sexually active individuals under 25 years of age, and those who have had a new sexual partner or more than one partner in the previous year [10]. In the USA, similar recommendations target women, and are extended to young males with high chlamydia prevalence [11]. Repeat testing after initial infection has been found to be beneficial, since repeated chlamydia infections are common [12-14], with recommendations for re-testing of chlamydia positive individuals varying between $3-12$ months in different countries $[10,11]$.

Sweden has no restrictions on chlamydia testing; anyone who wishes to be tested has the opportunity to do so. The official recommendation is aimed at persons with a recent new partner or who have had unprotected sexual contact [15]. Testing is based on opportunistic screening (testing) of adolescents and 
young adults aged 15-29 years, with the intention of increasing testing coverage as part of the National Action Plan for Chlamydia Prevention [16]. The number of reported chlamydia tests increased consistently between 2009 (496 522) and 2018 (591 460), with chlamydia positivity dropping from 7.6$5.4 \%$ during the period [17]. Interned-based testing likely contributed to this, accounting for over $20 \%$ of all chlamydia tests in 2018 [18].

Independent factors associated with repeated testing were reported elsewhere, that is, younger than 25 years, female sex, co-infection with HIV or gonorrhoea, and increased number of sexual partners during the previous 6 months [19-21]. However, single sexual behaviours might be risky not on their own but most likely in combination with other behaviours. In classical regression analysis (i.e., variable-oriented) analysis, the association between independent variable and outcome variable is examined while holding other variables constant. In contrast, a person-oriented analysis approach, such as latent class analysis (LCA), captures how multiple variables co-occur and interact with each other [22] [23]. This approach allows a multidimensional perspective, where sexual behaviour, substance use, and demographic variables interconnect. It can unmask subgroups (classes) of individuals within the population of interest.

We initiated the present study to gain a better knowledge about population subgroups tested repeatedly for chlamydia to contribute to the improvement of chlamydia prevention. We had two objectives: 1) to identify subgroups (latent classes) based on sexual behaviour and substance use patterns; 2) to study how membership of different latent classes is associated with repeated chlamydia testing and repeated chlamydia infection. Our hypothesis was that members of high-risk behaviour latent classes (LCs) are more likely to test repeatedly and acquire chlamydia repeatedly compared with low-risk behaviour classes.

\section{Materials And Methods}

Study participants

We used data from a published cohort study of visitors to an STI-clinic in Stockholm in 2008 who were tested for chlamydia [24]. Participants signed a written consent to link their answers in a questionnaire with the result of their test for chlamydia. The questionnaire included topics on sexual behaviour, testing behaviour and experience of substance use (see Table S1 in Online supplement) prior to providing a sample for chlamydia testing [25].

Measures

Manifest variables of sexual behaviour and substance use of latent class membership

To identify LCs, we initially selected 12 out of 26 variables related to sexual behaviour and substance use common to men and women. The selection was based on the published literature and our expert judgement (see variables and reasoning in Table S1). Because of the high correlation between "Selfperceived impact of drug use" and "Drug use", we decided to exclude the former from the analysis. Due to 
collinearity problems, we also excluded the variable "Type of last sex", as the majority of the cohort reported having had vaginal sex. We constructed one variable, "Current steady relationship and concurrent sexual contacts during past 12 months" out of "Current steady partnership" and "Concurrent partnerships during past 12 months" by collapsing categories (see the variable "Current steady relationship and concurrent sexual contacts during past 12 months", Table 1). We also collapsed response categories of the variables included in the LCA, since latent class models were not feasible owing to the small initial values in some of the initial response categories of the variables (see Table 1 with new categories). Missing data and the category "Do not remember" were collapsed, because neither provided any information. As a result, nine variables were included in the LCA (Table 1). 
Table 1

Variables $(n=9)$ included in the latent class analysis

\begin{tabular}{|c|c|c|c|}
\hline \multirow[t]{2}{*}{ Manifest variables } & $\begin{array}{l}\text { Women } \\
(n=1,378)\end{array}$ & $\begin{array}{l}\text { Men } \\
(n=1,436)\end{array}$ & $\begin{array}{l}\text { Total study } \\
\text { population } \\
(\mathrm{N}=2,814)\end{array}$ \\
\hline & $\begin{array}{l}\text { (\% of } \\
\text { column) }\end{array}$ & $\begin{array}{l}\text { (\% of } \\
\text { column) }\end{array}$ & $\mathbf{N}(\%$ of column) \\
\hline
\end{tabular}

\section{Main reason for current chlamydia testing}

- Safety and new partner requested and other

- Occasional Sex

- Contact with chlamydia case

- Symptoms

- Missing information

\section{Current steady relationship and concurrent sexual} contacts during past 12 months

- No steady partner and no or missing concurrent partners

- Yes steady partner and no concurrent partners

- Yes steady and yes concurrent partners

- Yes steady and missing concurrent partners

- Not applicable (since no reported steady partnership)

\section{Number of sexual partners during the past 12 months}

- 0-2 partners

- 3-5 partners

- $6+$ partners

- Missing information

\begin{tabular}{|c|c|c|}
\hline $\begin{array}{l}817 \\
(59.3)\end{array}$ & $785(54.7)$ & $1602(57.0$ \\
\hline $\begin{array}{l}205 \\
(14.9)\end{array}$ & $\begin{array}{l}235 \\
(16.4)\end{array}$ & $440(15.6)$ \\
\hline $\begin{array}{l}259 \\
(18.8)\end{array}$ & $\begin{array}{l}272 \\
(18.9)\end{array}$ & $531(18.9)$ \\
\hline $22(1.6)$ & 19 (1.3) & $41(1.5)$ \\
\hline $75(5.4)$ & $125(8.7)$ & $200(7.11)$ \\
\hline
\end{tabular}

628

(45.6)

643

(44.8)

324

(23.5)

261

(18.2)

183

(13.3)

278

(19.4)

237

(17.2)

249

(17.3)

$6(0.4)$

$5(0.4)$

$11(0.4)$

$1271(45.2)$

$585(20.8)$

461 (16.4)

486 (17.3)

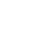




\begin{tabular}{|c|c|c|c|}
\hline \multirow[t]{2}{*}{ Manifest variables } & $\begin{array}{l}\text { Women } \\
(n=1,378)\end{array}$ & $\begin{array}{l}\text { Men } \\
(n=1,436)\end{array}$ & $\begin{array}{l}\text { Total study } \\
\text { population } \\
(\mathrm{N}=2,814)\end{array}$ \\
\hline & $\begin{array}{l}\text { (\% of } \\
\text { column) }\end{array}$ & $\begin{array}{l}\text { (\% of } \\
\text { column) }\end{array}$ & $\mathrm{N}$ (\% of column) \\
\hline \multicolumn{4}{|c|}{ Type of the last sexual partner } \\
\hline - Steady partner & $\begin{array}{l}428 \\
(31.1)\end{array}$ & $\begin{array}{l}396 \\
(27.6)\end{array}$ & $824(29.3)$ \\
\hline - Recurrent partner & $\begin{array}{l}411 \\
(29.8)\end{array}$ & $\begin{array}{l}341 \\
(23.8)\end{array}$ & $752(26.7)$ \\
\hline - Casual unknown partner & $111(8.1)$ & $\begin{array}{l}174 \\
(12.1)\end{array}$ & $285(10.1)$ \\
\hline - Casual known partner & $\begin{array}{l}138 \\
(10.0)\end{array}$ & $141(9.8)$ & $279(9.9)$ \\
\hline - Other type & $116(8.4)$ & $111(7.7)$ & $227(8.1)$ \\
\hline - Missing information & $\begin{array}{l}174 \\
(12.6)\end{array}$ & $\begin{array}{l}273 \\
(19.0)\end{array}$ & $447(15.9)$ \\
\hline \multicolumn{4}{|c|}{ Condom use with new/ casual partners } \\
\hline - Never or seldom & $\begin{array}{l}383 \\
(27.8)\end{array}$ & $\begin{array}{l}460 \\
(32.0)\end{array}$ & $843(30.0)$ \\
\hline - Often or always & $\begin{array}{l}987 \\
(71.6)\end{array}$ & $\begin{array}{l}969 \\
(67.5)\end{array}$ & $1956(69.5)$ \\
\hline - Missing information & $8(0.6)$ & $7(0.5)$ & $15(0.5)$ \\
\hline \multicolumn{4}{|c|}{ Taking responsibility for obtaining condom } \\
\hline - Never or often not & $\begin{array}{l}341 \\
(24.8)\end{array}$ & $\begin{array}{l}221 \\
(15.4)\end{array}$ & $562(20.0)$ \\
\hline - Sometimes & $\begin{array}{l}668 \\
(48.5)\end{array}$ & $\begin{array}{l}620 \\
(43.2)\end{array}$ & $1288(45.8)$ \\
\hline - Always & $\begin{array}{l}362 \\
(26.3)\end{array}$ & $\begin{array}{l}589 \\
(41.0)\end{array}$ & $951(33.8)$ \\
\hline - Missing information & $7(0.5)$ & $6(0.4)$ & $13(0.5)$ \\
\hline \multicolumn{4}{|c|}{ Alcohol use before having sex (past 6 months) } \\
\hline - No & $133(9.7)$ & $110(7.7)$ & $243(8.6)$ \\
\hline
\end{tabular}




\begin{tabular}{|c|c|c|c|}
\hline \multirow[t]{2}{*}{ Manifest variables } & $\begin{array}{l}\text { Women } \\
(n=1,378)\end{array}$ & $\begin{array}{l}\text { Men } \\
(n=1,436)\end{array}$ & $\begin{array}{l}\text { Total study } \\
\text { population } \\
(\mathrm{N}=2,814)\end{array}$ \\
\hline & $\begin{array}{l}\text { (\% of } \\
\text { column) }\end{array}$ & $\begin{array}{l}\text { (\% of } \\
\text { column) }\end{array}$ & $\mathrm{N}$ (\% of column) \\
\hline - Sometimes & $\begin{array}{l}457 \\
(33.2)\end{array}$ & $\begin{array}{l}388 \\
(27.0)\end{array}$ & $845(30.0)$ \\
\hline - Several time and don't remember & $\begin{array}{l}783 \\
(56.8)\end{array}$ & $\begin{array}{l}930 \\
(64.8)\end{array}$ & $1713(61.0)$ \\
\hline - Missing information & $5(0.4)$ & $8(0.6)$ & $13(0.4)$ \\
\hline \multicolumn{4}{|c|}{$\begin{array}{l}\text { Alcohol impact on taking higher sexual risks than } \\
\text { expected by respondent }\end{array}$} \\
\hline - No and little impact & $538(39.0$ & $520(36.2$ & $1058(37.6)$ \\
\hline - Some impact & $\begin{array}{l}482 \\
(35.0)\end{array}$ & $\begin{array}{l}531 \\
(37.0)\end{array}$ & $1013(36.0)$ \\
\hline - Big impact and don't remember & $\begin{array}{l}204 \\
(14.8)\end{array}$ & $\begin{array}{l}249 \\
(17.3)\end{array}$ & $453(16.1)$ \\
\hline - Not applicable, did not drink & $133(9.7)$ & $110(7.7)$ & $243(8.6)$ \\
\hline - Missing information & $21(1.5)$ & $26(1.8)$ & $47(1.6)$ \\
\hline \multicolumn{4}{|c|}{ Drug use before having sex (past 6 months) } \\
\hline - No & $\begin{array}{l}1246 \\
(90.4)\end{array}$ & $\begin{array}{l}1264 \\
(88.0)\end{array}$ & $2510(89.2)$ \\
\hline - Any use or don't remember & $116(8.4)$ & $\begin{array}{l}161 \\
(11.2)\end{array}$ & $277(9.8)$ \\
\hline - Missing information & $16(1.2)$ & $11(0.8)$ & $27(1.0)$ \\
\hline
\end{tabular}

Demographic and sex-specific variables across latent classes

We described the probabilities resulting from the LCA for covariates common to men and women and for covariates specific to each sex. Common covariates were age group and marital status, while sex-specific covariates were "Got woman unintentionally pregnant" for men; and for women, "Use of contraception method", "Use of emergency contraceptive pills", and "History of induced abortion".

Distal outcomes

We investigated the association between LCs and two outcomes: testing and being infected with chlamydia. For each outcome, we looked at short-term and long-term measures (Table 2). For short-term 
testing, we looked at repeated testing for chlamydia during the past 12 months (no/yes). For long-term testing, we analysed repeated lifetime testing for chlamydia (no; 1-3 times; four or more times).

Accordingly, for chlamydia infection short-term, we looked at current chlamydia test results at the time of recruitment (negative/positive), and for long-term outcomes, repeated lifetime chlamydia infection (never; once; twice or more times). No and never were considered as reference levels in all outcome analyses. 
Table 2

Distal outcome variables

\section{Outcome variables}

$\begin{array}{lll}\begin{array}{l}\text { Women } \\ (n=1,378)\end{array} & \text { Men } & \begin{array}{l}\text { Total study } \\ \text { population }\end{array} \\ \begin{array}{l}(\mathrm{n}=1,436) \\ \text { column})\end{array} & \begin{array}{l}\text { (\% of } \\ \text { column })\end{array} & \mathrm{N}(\mathrm{N}=2,814) \\ \end{array}$

Short-term testing outcome: Chlamydia testing during the past 12 months -

- Yes

715

(51.9)

494

(34.4)

- No

534

(38.8)

642

(44.7)

- Don't remember and missing information

$129(9.4)$
$1209(42.9)$

$1176(41.8)$

$429(15.2)$

300

(20.9)

\section{Long-term testing outcome: Lifetime testing for} chlamydia

- Never

$103(7.5)$

350

(24.4)

$-1-3$ times

875

(63.5)

862

$(60.0)$

$-\geq 4$ times

375

(27.2)

198

(13.8)

$25(1.8) \quad 26(1.8)$

$51(1.8)$

- Don't remember and missing information

Short-term infection outcome: Present chlamydia infection

- Yes

$122(8.8)$

- No

1256

(91.2)

$453(16.1)$

$1737(61.7)$

$573(20.4)$

Long-term infection outcome: Lifetime chlamydia infection

- Never

805

(58.4)

- Once

$-\geq 2$ times

- Missing information and don't remember

\section{0}

(26.9)

110 (8.0)

$93(6.8)$
181

(12.6)

1255

(87.4)

\section{2}

(49.6)

317

(22.1)

303 (10.8)

2511 (89.2)

(22.1)

92 (6.4)

315

(21.9)
202 (7.2)

1,517 (53.9)

$687(24.4)$

408 (14.5) 


\section{Age group (included as confounder)}

\begin{tabular}{|llll|}
\hline$-20-24$ & 465 & 367 & $832(29.6)$ \\
\hline$-25-29$ & $(33.7)$ & $(25.6)$ & \\
& 583 & 626 & $1209(42.9)$ \\
\hline$-30-34$ & $(42.3)$ & $(43.6)$ & \\
& 219 & 304 & $523(18.6)$ \\
$-35-40$ & $(15.9)$ & $(21.2)$ & \\
\hline
\end{tabular}

Due to differences in sexual behaviour, we carried out the analyses for each sex independently, and we adjusted for age group (20-24, 25-29, 30-34 and 35-40 years; with the latter as a reference level). Statistical analyses

Latent class models with varying numbers of LCs (2-5) were fitted, based on the observed 9 manifest variables. We selected the model with the optimal number of LCs based on the Akaike Information Criterion (AIC) and the Bayesian Information Criterion (BIC). We also calculated entropy for each LC model; entropy with values approaching the value of one indicates clearer separated latent classes [26]. The conditional response probabilities and LC prevalence were estimated using the maximum likelihood criterion. Each respondent was assigned to the LC with the highest probability. We labelled LC based on the item-response probabilities of the respondents and ordered them according to risk-behaviour for chlamydia; class 1 comprised individuals with low-risk behaviour, which also suited as a reference level in all analyses.

We assessed the association between LC membership and distal outcomes. We fitted proportional odds ordinal logistic regression models with the identified LCs as an independent variable and adjusted for age group [27]. The main assumption in this model was that the relationship between all categories of the outcome is the same, hence the name proportional odds model. To test this assumption, we performed a Brant test [28], which is non-significant $(P$-value $>0.05)$ when a proportional odds assumption is not violated. For the outcome "Lifetime chlamydia infection" in men, the assumption was not met, so we used the multinomial (polytomous) logistic regression model instead; this allows for varying relationships between categories of the outcome (contrasting proportional odds between categories of outcome) [29]. For the long-term distal outcomes, we also performed a linear trend test (Wald test). We reported adjusted odds ratios (adjORs) with 95\% confidence intervals (Cls).

We used Stata v. 15 for all analyses [30] and used R statistical software to produce the graphs [31].

\section{Results}

\section{Study participants}


We recruited 2814 individuals, of whom 1436 (51\%) were men [24]. The age of the respondents was 20 to 40 years, with a mean age for the women $27.0( \pm 4.3)$ years and a mean age for the men 27.8 ( \pm 4.4$)$ years. Two thirds of the men and women were single [24].

\section{Latent Classes}

Based on the nine selected manifest variables, we fitted models with two to five LCs for the men and up to three LCs for the women (because the models with more than three classes did not converge). The AIC and BIC indicated optimal models, with five classes for the men and three classes for the women (Figure 1, Online supplement Table $2 S$ ). Additionally, the highest entropy value (0.85) indicated that the optimal model for the men was a four-class model (Online supplement Table 2S).

We interpreted, labelled, and ordered the LCs based on the item-response probabilities (Online supplement Table 3S-4S), with class 1 being the least risky behaviour, and class 4 for the men and class 3 for the women, the riskiest behaviour. We present the frequency of the highest risk category of each variable in Figures 1 and 2. For the men, 8\% ( $n=110)$ fell into class 1, labelled "Mixed steady and non-steady partnerships, low substance use" (Table 3S). Thirty percent $(n=441)$ of the men fell into the class 2 , labelled "Steady partnership with/without concurrent partners", They were considered medium risk, with a low probability of not having a steady current relationship and a higher probability of many sexual partners with and without concurrent relationships. For the men, we could further separate LCs of highrisk behaviour: "Non-steady partnerships with many partners, condom users" (class 3, n = 601) and "Nonsteady partnerships with many partners, condom non-users" (class $4, n=284$ ). These contained $42 \%$ and $20 \%$ of the men, respectively (Table 3 S).

Amongst the women, 10\% $(n=134)$ fell into class 1 of low-risk sexual behaviour, labelled "Mixed steady and non-steady partnerships, low substance use" (Online supplement Table 4S). Thirty-two percent ( $\mathrm{n}=$ 441) of the women fell into the class 2, labelled "Steady partnership with/without concurrent partners" (medium risk). The largest class 3, containing 58\% $(n=803)$ of the women, was labelled "Non-steady partnerships with many partners", and was characterised by a high probability of having a non-steady current partner and a higher probability of having 6 or more sexual partners during the previous 12 months compared with the other female LCs. The probability of frequent alcohol use before sex was high amongst the women and men across all LCs, with the exception of class 1.

\section{Demographic and sex-specific variables across latent classes}

Class membership was similar amongst the men and women across the age groups and marital status (Online supplement Table 5S - 6S). Notably, the younger (20-29 years of age) men (76\%) and women (77\%), and single men (88\%) and women (96\%) were more likely to belong to high-risk classes (4 and 3, respectively). The men in class 4 were also more likely (40\%) to impregnate women unintentionally than in other LCs. The absolute majority (80-87\%) of the women used some type of contraception across LCs. However, the women in class 3 were more likely to use the barrier method (35\%). There was no major difference in the use of emergency contraceptive pills or a history of induced abortion across LCs. 


\section{Distal outcomes}

\section{Short-term outcome: repeated testing during past 12 months and current chlamydia infection}

For repeated testing for chlamydia during past 12 months, we found significantly higher odds of 1.72 (95\% Cl: 1.16 - 2.54) in high-risk behaviour class 3 compared with class 1 (Figure 3, Online supplement Table 7S) amongst the women. There was a borderline association with high-risk behaviours class 3 amongst the men, adjOR $=1.60$ (95\%Cl: $0.97-2.65)$, Figure 3, Online supplement Table 8S.

Amongst the men, class 4 had a $3.03(95 \% \mathrm{Cl} 1.32-6.93)$ times higher odds than class 1 of testing positive for the current chlamydia infection (Figure 4, Online supplement Table 9S). Class 3 in the men had borderline significant increased odds as well: adjOR $=2.16(95 \% \mathrm{Cl}: 0.97-4.83)$. None of the associations were statistically significant for this outcome amongst the women (Figure 4, Online supplement Table 10S).

\section{Long-term outcome: repeated lifetime testing and repeated lifetime chlamydia infection}

Both high-risk male classes and the high-risk female class were all significantly associated with at least a two-fold increased odds of repeated lifetime testing (Figure 3, Online supplement Table 7S-8S). Amongst the men, class 3 had an adjOR $=2.26(95 \% \mathrm{Cl}: 1.50-3.40)$, while class 4 had an even higher association: adjOR =3.03 (95\%Cl: $1.93-4.74)$, Figure 3 and Online supplement Table 8S. Amongst the women, we estimated a 1.85 ( $95 \% \mathrm{Cl}: 1.24-2.76$ ) higher odds of repeated lifetime testing in high-risk class 3 than class 1 . For this outcome, in both the men and women, we estimated a significant linear trend, which indicated a dose-response relationship: increasing levels of risk behaviour LCs were associated with an increased odds of repeated lifetime testing for chlamydia.

Furthermore, all LCs were associated with having had repeated lifetime chlamydia infection amongst the men, and the odds increased with each level of the outcome (never, once, twice or more). Class 3 had a 1.84 (95\% Cl: $1.03-3.26$ ) higher odds than class 1 of having had chlamydia once during their lifetime compared with never. Class 4 had a 2.54 (95\% Cl: 1.39 - 4.64) higher odds than class 1 of one chlamydia infection during their lifetime compared with never. The odds of having chlamydia twice or more compared with having had it once varied across LCs amongst the men, though they were not statistically significant (Online supplement Table 9S). Amongst the women, none of the associations were statistically significant for lifetime repeated chlamydia infection (Figure 4, Online supplement Table 10S).

\section{Discussion}

In a large cohort of visitors to the STI-clinic, we were able to identify four distinct LCs for the men and three LCs for the women. They represented a diversity of sexual behaviour, and ranged from low- to highrisk for chlamydia. The women in the high-risk class were more likely to test repeatedly for chlamydia during the past 12 months but not men. This was not the case amongst the high-risk class men. Both men and women in the high-risk classes had at least a two-fold higher odds of being tested repeatedly 
during their lifetime compared with the lowest risk class. The men in the high-risk classes had a two-fold higher odds of being infected once during their lifetime and a three-fold higher odds of having a current chlamydia infection. No associations between LC membership and chlamydia infection were found amongst the women.

The majority (60\%) of respondents of both sexes fell into high-risk LCs, which may have been expected given that the entire cohort was recruited at an STI-clinic, where a higher proportion of individuals with high-risk behaviour are more likely to be presented, as has been noted elsewhere [32-34]. Important discriminators in our class profiles were condomless sex with casual partners; number of sexual partners during the previous 12 months; and type of current sexual partnership (steady vs non-steady). Several related studies have reported that respondents consider it important to use condoms and have the intention to use them, but actual use varies with the type of partner and the form of sexual contact [3539]. This was reflected amongst the men in our study, where further separation of the high-risk classes was possible; one class was described as condom users (class 3 ) and the other non-condom users (class 4). An increased number of sexual partners is known to be an independent risk factor for chlamydia [40, $41,24]$. In our LCA, however, we found that this also interrelated with decreased condom use in high- and moderate-risk LCs. The moderate -risk sexual behaviour class was also characterised by a high probability of concurrent (casual) partnerships, despite a high proportion of current steady partnerships. Similar LCs were reported elsewhere as a significant facilitator of STI acquisition [42-45].

Pre-sex alcohol use was highly prevalent in moderate- and high-risk classes in our study. This contributes to sexual risk-taking, because it can lead to poor judgement on sexual partner choice (e.g., casual partner), an increased number of sexual partners, condomless sex, and regrets about having had sex [4649]. However, other studies have suggested that people who fail to use condoms after drinking possibly also fail to use them when they abstain from drinking; such behaviour is believed to be more likely related to personality traits $[50,51]$. Furthermore, within the moderate- and high-risk LCs in our study, alcohol use interacted with the use of other drugs - cannabis was the most frequently cited. Combined substance use (i.e., alcohol and drugs) has been described elsewhere; study participants reported that the purpose was to facilitate sexual contact and to enhance the sensations of sexual intercourse [46].

We found that individuals of high-risk classes had a higher odds of being tested repeatedly, This suggested that they had absorbed public health messages to have tests for chlamydia after unprotected sexual contact with a new or casual partner [16]. A study in Stockholm County reported (after controlling for social-economic factors and previous positive chlamydia test) that $42 \%$ of young people had tested repeatedly for chlamydia within a 3-year period [19]. Repeated testing after chlamydia infection due to unchanged risky behaviour has been discussed elsewhere [19, 52, 20,53]. It was recently reported that young adults who engage in unsafe sex possibly have repeated tests for chlamydia as a replacement for condom use [54]. The same study found that repeated testing gave a false sense of security when the chlamydia test was negative, while a positive chlamydia test resulted in repeated testing, but did not encourage changes in sexual behaviour [54]. Studies have shown consistently that repeated testing may facilitate short-term change in high-risk behaviour if individuals receive positive chlamydia results $[55,56]$ 
but not negative results [57], suggesting that testing has unintended consequences [58-60]. It has been argued that introducing a screening program for chlamydia in low -risk populations, where many individuals test negative and might therefore change their sexual behaviour in the direction of greater risk, could hamper screening efforts [57]. As a result, a high prevalence of repeated chlamydia infections has been reported amongst men and women $[61,62]$. Our results show that men in the high-risk classes were more likely to test positive for present chlamydia and at least once during their lifetime, which suggests that they did not change their sexual behaviour. Another LC study confirmed our findings (in the case of classes 3 and 4) that casual sex risk-takers were more likely to contract STIs [63, 64]. By contrast, we did not find any increased odds of positive chlamydia results amongst the women; in other words, the presence of chlamydia did not differ according to risk behaviour class (i.e., it was more homogeneous).

Our results indicated that risky sexual behaviour (e.g., condomless sexual contacts with casual partners, and higher numbers of sexual partners) were still at high levels amongst the men and at moderate levels for women in the high-risk classes (class 4 and 3, respectively). Another, more recent study in Sweden suggested that young adults might apply repeated testing as a behavioural strategy to avoid using condoms, with no corresponding change in sexual behaviour [65]. Condoms are effective in reducing the risk of chlamydia acquisition [66], and modelling studies have shown that high levels of condom use reduce chlamydia prevalence substantially $[67,68]$. Alcohol use was highly prevalent amongst our study participants, and therefore attempts to increase condom use might be combined with interventions to decrease alcohol use: this might encourage condom-related protective behavioural strategies in individuals $[69,50]$.

To the best of our knowledge, the present study is the first to associate sexual risk-behaviour LC membership with repeated testing for chlamydia, and our LCA was reinforced by the large sample size and the distinction it drew between the sexes. However, one of its major limitations is that it relies on an accurate selection of observed variables to identify latent classes. Additionally, recall bias and self-report bias are common in studies based on self-reported data. Another limitation is that our study population was not randomly sampled from the general population. The fact that they were visitors at an STI-clinic suggests selection bias. Besides, we used different recall times for exposure (6 months and 12 months) and outcomes (12 months and across lifetimes). This may have biased in the observed associations. However, a recent LCA study in a similar setting reported that the majority of its population remained in the same LC for up to one year, which was an indication of relatively stable sexual behaviour [32]. Finally, no causal inference can be drawn from the present study because of potential unmeasured confounding and a lack of temporality.

In conclusion, LCs of high-risk sexual behaviour were associated with the repeated lifetime testing for chlamydia (amongst both sexes) and repeated testing during the previous 12 months (amongst the women). This suggested that current public health messages regarding STI tests were being acted on. However, borderline association with repeated chlamydia infection in men suggests that they are at risk for infection. Efforts at prevention should be stepped up, and these should include the promotion of safe 
sex. More tailored interventions in terms of the sexes and different risk-behaviour patterns should be considered.

\section{Abbreviations}

\begin{tabular}{|ll|}
\hline AIC & Akaike Information Criterion \\
\hline adjOR & Adjusted Odds Ratio \\
\hline BIC & Bayesian Information Criterion \\
\hline CI & Confidence interval \\
\hline LC & Latent class \\
\hline LCA & Latent class analysis \\
\hline STI & Sexually transmitted infection \\
\hline
\end{tabular}

\section{Declarations}

Ethics approval and consent to participate: was granted by Regional Ethics Review Board in Stockholm (reference number: 2007/933-31/4 and 2011/313-32). No administrative permissions were required to access the raw data used in this study.

Consent for publication: Not applicable.

Availability of data and materials: The data that support the findings of this study are available from Public Health Agency of Sweden but restrictions apply to the availability of these data, which were used under license for the current study, and so are not publicly available. Data are however available from the authors upon reasonable request and with permission of Public Health Agency of Sweden.

Competing interests: None.

Funding: None.

\section{Authors' contributions:}

IV conceptualized the study, developed analysis plan, conducted data management and statistical analyses, and wrote the manuscript;

AP contributed to development of the analysis plan, supervised and contributed to the statistical analyses and critically reviewed manuscript;

LM contributed to development of the analysis plan, critically reviewed the manuscript;

PS contributed to development of the analysis plan, critically reviewed the manuscript; 
$\mathrm{BH}$ contributed to development of the analysis plan, critically reviewed the manuscript;

SKB conceptualized the study, contributed to development of the analysis plan, supervised the statistical analyses and critically reviewed the manuscript.

All authors have read and approved the final version of the manuscript.

\section{Acknowledgements: None.}

\section{References}

1. Newman L, Rowley J, Vander Hoorn S, Wijesooriya NS, Unemo M, Low N, et al. Global Estimates of the Prevalence and Incidence of Four Curable Sexually Transmitted Infections in 2012 Based on Systematic Review and Global Reporting. PLoS One. 2015;10(12):e0143304. doi:10.1371/journal.pone.0143304.

2. Davies B, Turner KME, Frolund M, Ward H, May MT, Rasmussen S, et al. Risk of reproductive complications following chlamydia testing: a population-based retrospective cohort study in Denmark. The Lancet Infectious diseases. 2016;16(9):1057-64. doi:10.1016/S1473-3099(16)300925.

3. den Heijer CDJ, Hoebe C, Driessen JHM, Wolffs P, van den Broek IVF, Hoenderboom BM, et al. Chlamydia trachomatis and the Risk of Pelvic Inflammatory Disease, Ectopic Pregnancy, and Female Infertility: A Retrospective Cohort Study Among Primary Care Patients. Clin Infect Dis. 2019;69(9):1517-25. doi:10.1093/cid/ciz429.

4. Hoenderboom BM, van Benthem BHB, van Bergen J, Dukers-Muijrers N, Gotz HM, Hoebe C, et al. Relation between Chlamydia trachomatis infection and pelvic inflammatory disease, ectopic pregnancy and tubal factor infertility in a Dutch cohort of women previously tested for chlamydia in a chlamydia screening trial. Sex Transm Infect. 2019;95(4):300-6. doi:10.1136/sextrans-2018053778.

5. Reekie J, Donovan B, Guy R, Hocking JS, Kaldor JM, Mak D, et al. Risk of Ectopic Pregnancy and Tubal Infertility Following Gonorrhea and Chlamydia Infections. Clin Infect Dis. 2019;69(9):1621-3. doi:10.1093/cid/ciz145.

6. Reekie J, Donovan B, Guy R, Hocking JS, Kaldor JM, Mak DB, et al. Risk of Pelvic Inflammatory Disease in Relation to Chlamydia and Gonorrhea Testing, Repeat Testing, and Positivity: A Population-Based Cohort Study. Clin Infect Dis. 2018;66(3):437-43. doi:10.1093/cid/cix769.

7. Detels R, Green AM, Klausner JD, Katzenstein D, Gaydos C, Handsfield H, et al. The incidence and correlates of symptomatic and asymptomatic Chlamydia trachomatis and Neisseria gonorrhoeae infections in selected populations in five countries. Sexually transmitted diseases. 2011;38(6):5039.

8. Korenromp EL, Sudaryo MK, de Vlas SJ, Gray RH, Sewankambo NK, Serwadda D, et al. What proportion of episodes of gonorrhoea and chlamydia becomes symptomatic? Int J STD AIDS. 
2002;13(2):91-101. doi:10.1258/0956462021924712.

9. European Centre for Disease Prevention and Control. Guidance on chlamydia control in Europe 2015. Stockholm2016.

10. Lanjouw E, Ouburg S, de Vries HJ, Stary A, Radcliffe K, Unemo M. 2015 European guideline on the management of Chlamydia trachomatis infections. Int J STD AIDS. 2016;27(5):333-48. doi:10.1177/0956462415618837.

11. Workowski KA, Bolan GA, Centers for Disease C. Prevention. Sexually transmitted diseases treatment guidelines, 2015. MMWR Recommendations and reports: Morbidity and mortality weekly report Recommendations and reports. 2015;64(RR-03):1-137.

12. Gotz HM, Wolfers ME, Luijendijk A, van den Broek IV. Retesting for genital Chlamydia trachomatis among visitors of a sexually transmitted infections clinic: randomized intervention trial of homeversus clinic-based recall. BMC Infect Dis. 2013;13:239. doi:10.1186/1471-2334-13-239.

13. Klovstad H, Natas O, Tverdal A, Aavitsland P. Systematic screening with information and home sampling for genital Chlamydia trachomatis infections in young men and women in Norway: a randomized controlled trial. BMC Infect Dis. 2013;13:30. doi:10.1186/1471-2334-13-30.

14. van der Helm JJ, Koekenbier RH, van Rooijen MS, Schim van der Loeff MF, de Vries HJC. What Is the Optimal Time to Retest Patients With a Urogenital Chlamydia Infection? A Randomized Controlled Trial. Sexually transmitted diseases. 2018;45(2):132-7. doi:10.1097/OLQ.0000000000000706.

15. Läkemedelsverket (Swedish Medical Products Agency). Sexuellt överförbara bakteriella infektioner behandlingsrekommendation: Läkemedelsverket2015.

16. The National Board of Health and Welfare of Sweden. The National Action Plan for Chlamydia Prevention with focus on young people aged 15-29 years. Stockholm2009. Report No.: 2009-126180.

17. Folkhälsomyndigheten K. 2019. Folkhälsomyndigheten, Stockholm, Sweden. 2019. https://www.folkhalsomyndigheten.se/folkhalsorapportering-statistik/statistik-ao/sjukdomsstatistik/klamydiainfektion/?p=76949\#statistics-nav. Accessed December 15, 2020.

18. Soderqvist J, Gullsby K, Stark L, Wikman M, Karlsson R, Herrmann B. Internet-based self-sampling for Chlamydia trachomatis testing: a national evaluation in Sweden. Sex Transm Infect. 2020;96(3):160-5. doi:10.1136/sextrans-2019-054256.

19. Nielsen A, Marrone G, De Costa A. Chlamydia trachomatis among Youth - Testing Behaviour and Incidence of Repeat Testing in Stockholm County, Sweden 2010-2012. PLoS One. 2016;11(9):e0163597. doi:10.1371/journal.pone.0163597.

20. Wijers J, Dukers-Muijrers N, Hoebe C, Wolffs PFG, van Liere G. The characteristics of patients frequently tested and repeatedly infected with Chlamydia trachomatis in Southwest Limburg, the Netherlands. BMC Public Health. 2020;20(1):1239. doi:10.1186/s12889-020-09334-9.

21. Visser M, van Aar F, Koedijk FDH, Kampman CJG, Heijne JCM. Repeat Chlamydia trachomatis testing among heterosexual STI outpatient clinic visitors in the Netherlands: a longitudinal study. BMC Infect Dis. 2017;17(1):782. doi:10.1186/s12879-017-2871-1. 
22. Formann AK, Kohlmann T. Latent class analysis in medical research. Stat Methods Med Res. 1996;5(2):179-211. doi:10.1177/096228029600500205.

23. Collins Linda M, Lanza Stephanie T. Latent Class And Latent Transition Analysis. Wiley Series in Probability and Statistics. Hoboken: John Wiley \& Sons, Inc.; 2010.

24. Velicko I, Ploner A, Sparen P, Marions L, Herrmann B, Kuhlmann-Berenzon S. Sexual and testing behaviour associated with Chlamydia trachomatis infection: a cohort study in an STI clinic in Sweden. BMJ open. 2016;6(8):e011312. doi:10.1136/bmjopen-2016-011312.

25. Edgardh K, Kuhlmann-Berenzon S, Grunewald M, Rotzen-Ostlund M, Qvarnstrom I, Everljung J. Repeat infection with Chlamydia trachomatis: a prospective cohort study from an STI-clinic in Stockholm. BMC Public Health. 2009;9:198. doi:10.1186/1471-2458-9-198.

26. Aldana-Bobadilla E, Kuri-Morales A. A Clustering Method Based on the Maximum Entropy Principle. Entropy. 2015;17(1):151-80. doi:10.3390/e17010151.

27. Bender R, Grouven U. Ordinal logistic regression in medical research. J R Coll Physicians Lond. 1997;31(5):546-51.

28. Richard W. Generalized ordered logit/partial proportional odds models for ordinal dependent variables. The Stata Journal. 2006;6(Number 1):58-82.

29. Kwak C, Clayton-Matthews A. Multinomial logistic regression. Nurs Res. 2002;51(6):404-10. doi:10.1097/00006199-200211000-00009.

30. STATA version 15. Stata Statistical Software: Release 15. College Station. TX:: Stata Corp LLC; 2017.

31. Team RC. R: A language and environment for statistical computing. Vienna: R Foundation for Statistical Computing; 2017.

32. van Wees DA, Heijne JCM, Basten M, Heijman T, de Wit J, Kretzschmar MEE, et al. Longitudinal Patterns of Sexually Transmitted Infection Risk Based on Psychological Characteristics and Sexual Behavior in Heterosexual Sexually Transmitted Infection Clinic Visitors. Sexually transmitted diseases. 2020;47(3):171-6. doi:10.1097/OLQ.0000000000001110.

33. Vasilenko SA, Kugler KC, Butera NM, Lanza ST. Patterns of adolescent sexual behavior predicting young adult sexually transmitted infections: a latent class analysis approach. Arch Sex Behav. 2015;44(3):705-15. doi:10.1007/s10508-014-0258-6.

34. Xu Y, Norton S, Rahman Q. Adolescent Sexual Behavior Patterns in a British Birth Cohort: A Latent Class Analysis. Arch Sex Behav. 2020. doi:10.1007/s10508-019-01578-w.

35. Darj E, Bondestam K. [Adolescents' view on the use of condoms]. Lakartidningen. 2003;100(44):3510-2, 5-6.

36. Eleftheriou A, Bullock S, Graham CA, Skakoon-Sparling S, Ingham R. Does attractiveness influence condom use intentions in women who have sex with men? PLoS One. 2019;14(5):e0217152. doi:10.1371/journal.pone.0217152.

37. Fridlund V, Stenqvist K, Nordvik MK. Condom use: the discrepancy between practice and behavioral expectations. Scandinavian journal of public health. 2014;42(8):759-65. 
doi:10.1177/1403494814550518.

38. Lescano CM, Vazquez EA, Brown LK, Litvin EB, Pugatch D, Project SSG. Condom use with "casual" and "main" partners: what's in a name? The Journal of adolescent health: official publication of the Society for Adolescent Medicine. 2006;39(3):443 e1-7. doi:10.1016/j.jadohealth.2006.01.003.

39. Senn TE, Scott-Sheldon LA, Carey MP. Relationship-specific condom attitudes predict condom use among STD clinic patients with both primary and non-primary partners. AIDS Behav. 2014;18(8):1420-7. doi:10.1007/s10461-014-0726-y.

40. de Coul EL, Warning TD, Koedijk FD, Dutch STIc. Sexual behaviour and sexually transmitted infections in sexually transmitted infection clinic attendees in the Netherlands, 2007-2011. Int J STD AIDS. 2014;25(1):40-51. doi:10.1177/0956462413491736.

41. Sonnenberg P, Clifton S, Beddows S, Field N, Soldan K, Tanton C, et al. Prevalence, risk factors, and uptake of interventions for sexually transmitted infections in Britain: findings from the National Surveys of Sexual Attitudes and Lifestyles (Natsal). Lancet. 2013;382(9907):1795-806. doi:10.1016/S0140-6736(13)61947-9.

42. Hock-Long L, Henry-Moss D, Carter M, Hatfield-Timajchy K, Erickson PI, Cassidy A, et al. Condom use with serious and casual heterosexual partners: findings from a community venue-based survey of young adults. AIDS Behav. 2013;17(3):900-13. doi:10.1007/s10461-012-0177-2.

43. Nesoff ED, Dunkle K, Lang D. The Impact of Condom Use Negotiation Self-Efficacy and Partnership Patterns on Consistent Condom Use Among College-Educated Women. Health education behavior: the official publication of the Society for Public Health Education. 2016;43(1):61-7. doi:10.1177/1090198115596168.

44. Rodrigues DL, Prada M, Lopes D. Perceived sexual self-control and condom use with primary and casual sex partners: age and relationship agreement differences in a Portuguese sample. Psychol Health. 2019;34(10):1231-49. doi:10.1080/08870446.2019.1603384.

45. Yamamoto N, Ejima K, Nishiura H. Modelling the impact of correlations between condom use and sexual contact pattern on the dynamics of sexually transmitted infections. Theor Biol Med Model. 2018;15(1):6. doi:10.1186/s12976-018-0078-9.

46. Bellis MA, Hughes K, Calafat A, Juan M, Ramon A, Rodriguez JA, et al. Sexual uses of alcohol and drugs and the associated health risks: a cross sectional study of young people in nine European cities. BMC Public Health. 2008;8:155. doi:10.1186/1471-2458-8-155.

47. George WH. Alcohol. and Sexual Health Behavior: "What We Know and How We Know It". J Sex Res. 2019;56(4-5):409-24. doi:10.1080/00224499.2019.1588213.

48. Grandahl M, Mohammad J, Larsson M, Herrmann B. Users' Opinions of Internet-based Self-sampling Tests for Chlamydia trachomatis and Neisseria gonorrhoeae in Sweden. Acta dermato-venereologica. 2020;100(18):adv00315. doi:10.2340/00015555-3677.

49. Griffin JA, Umstattd MR, Usdan SL. Alcohol use and high-risk sexual behavior among collegiate women: a review of research on alcohol myopia theory. J Am Coll Health. 2010;58(6):523-32. doi:10.1080/07448481003621718. 
50. Moylett S, Hughes BM. The associations among personality, alcohol-related Protective Behavioural Strategies (PBS), alcohol consumption and sexual intercourse in Irish, female college students. Addictive behaviors reports. 2017;6:56-64. doi:10.1016/j.abrep.2017.08.001.

51. Weinhardt LS, Carey MP. Does alcohol lead to sexual risk behavior? Findings from event-level research. Annual review of sex research. 2000;11:125-57.

52. Rose SB, Garrett SM, Stanley J, Pullon SRH. Retesting and repeat positivity following diagnosis of Chlamydia trachomatis and Neisseria gonorrhoea in New Zealand: a retrospective cohort study. BMC Infect Dis. 2017;17(1):526. doi:10.1186/s12879-017-2635-y.

53. Woodhall SC, Atkins JL, Soldan K, Hughes G, Bone A, Gill ON. Repeat genital Chlamydia trachomatis testing rates in young adults in England, 2010. Sex Transm Infect. 2013;89(1):51-6. doi:10.1136/sextrans-2012-050490.

54. Nielsen A, De Costa A, Danielsson KG, Salazar M. Repeat testing for chlamydia trachomatis, a "safe approach" to unsafe sex? a qualitative exploration among youth in Stockholm. BMC Health Serv Res. 2017;17(1):730. doi:10.1186/s12913-017-2681-6.

55. Crosby RA, DiClemente RJ, Wingood GM, Salazar LF, Rose E, Levine D, et al. Associations between sexually transmitted disease diagnosis and subsequent sexual risk and sexually transmitted disease incidence among adolescents. Sexually transmitted diseases. 2004;31(4):205-8. doi:10.1097/01.olq.0000114940.07793.20.

56. Diclemente RJ, Wingood GM, Sionean C, Crosby R, Harrington K, Davies S, et al. Association of adolescents' history of sexually transmitted disease (STD) and their current high-risk behavior and STD status: a case for intensifying clinic-based prevention efforts. Sexually transmitted diseases. 2002;29(9):503-9. doi:10.1097/00007435-200209000-00002.

57. Soetens LC, van Benthem BH, Op de Coul EL. Chlamydia test results were associated with sexual risk behavior change among participants of the Chlamydia screening implementation in The Netherlands. Sexually transmitted diseases. 2015;42(3):109-14.

doi:10.1097/OLQ.0000000000000234.

58. Sznitman S, Stanton BF, Vanable PA, Carey MP, Valois RF, Brown LK, et al. Long term effects of community-based STI screening and mass media HIV prevention messages on sexual risk behaviors of African American adolescents. AIDS Behav. 2011;15(8):1755-63. doi:10.1007/s10461-011-99466.

59. Sznitman SR, Carey MP, Vanable PA, DiClemente RJ, Brown LK, Valois RF, et al. The impact of community-based sexually transmitted infection screening results on sexual risk behaviors of African American adolescents. The Journal of adolescent health: official publication of the Society for Adolescent Medicine. 2010;47(1):12-9. doi:10.1016/j.jadohealth.2009.12.024.

60. van Wees DA, Drissen M, den Daas C, Heijman T, Kretzschmar MEE, Heijne JCM. The impact of STI test results and face-to-face consultations on subsequent behavior and psychological characteristics. Preventive medicine. 2020;139:106200. doi:10.1016/j.ypmed.2020.106200. 
61. Fung M, Scott KC, Kent CK, Klausner JD. Chlamydial and gonococcal reinfection among men: a systematic review of data to evaluate the need for retesting. Sex Transm Infect. 2007;83(4):304-9. doi:10.1136/sti.2006.024059.

62. Hosenfeld CB, Workowski KA, Berman S, Zaidi A, Dyson J, Mosure D, et al. Repeat infection with Chlamydia and gonorrhea among females: a systematic review of the literature. Sexually transmitted diseases. 2009;36(8):478-89. doi:10.1097/OLQ.0b013e3181a2a933.

63. Ann Lyons H. Heterosexual Casual Sex and STI Diagnosis: A Latent Class Analysis. International journal of sexual health: official journal of the World Association for Sexual Health. 2017;29(1):3247. doi:10.1080/19317611.2016.1210711.

64. Hill AV, De Genna NM, Perez-Patron MJ, Gilreath TD, Tekwe C, Taylor BD. Identifying Syndemics for Sexually Transmitted Infections Among Young Adults in the United States: A Latent Class Analysis. The Journal of adolescent health: official publication of the Society for Adolescent Medicine. 2019;64(3):319-26. doi:10.1016/j.jadohealth.2018.09.006.

65. Nielsen A, de Costa A, Gemzell-Danielsson K, Boman J, Salazar M. 'Repeat testing without having 'the talk' is not meaningful'-healthcare providers' perceptions on finding a balance between Chlamydia trachomatis testing and primary prevention strategies. A qualitative study in Stockholm, Sweden. BMJ open. 2020;10(8):e034179. doi:10.1136/bmjopen-2019-034179.

66. Warner L, Stone KM, Macaluso M, Buehler JW, Austin HD. Condom use and risk of gonorrhea and Chlamydia: a systematic review of design and measurement factors assessed in epidemiologic studies. Sexually transmitted diseases. 2006;33(1):36-51.

doi:10.1097/01.olq.0000187908.42622.fd.

67. Azizi A, Rios-Soto K, Mubayi A. J MH. A Risk-based Model for Predicting the Impact of using Condoms on the Spread of Sexually Transmitted Infections. Infectious Disease Modelling. 2017;2(1):100-12. doi:10.1016/j.idm.2017.02.004.

68. Kretzschmar M, van Duynhoven YT, Severijnen AJ. Modeling prevention strategies for gonorrhea and Chlamydia using stochastic network simulations. Am J Epidemiol. 1996;144(3):306-17. doi:10.1093/oxfordjournals.aje.a008926.

69. Gilmore AK, Granato HF, Lewis MA. The use of drinking and condom-related protective strategies in association with condom use and sex-related alcohol use. J Sex Res. 2013;50(5):470-9. doi:10.1080/00224499.2011.653607.

\section{Figures}




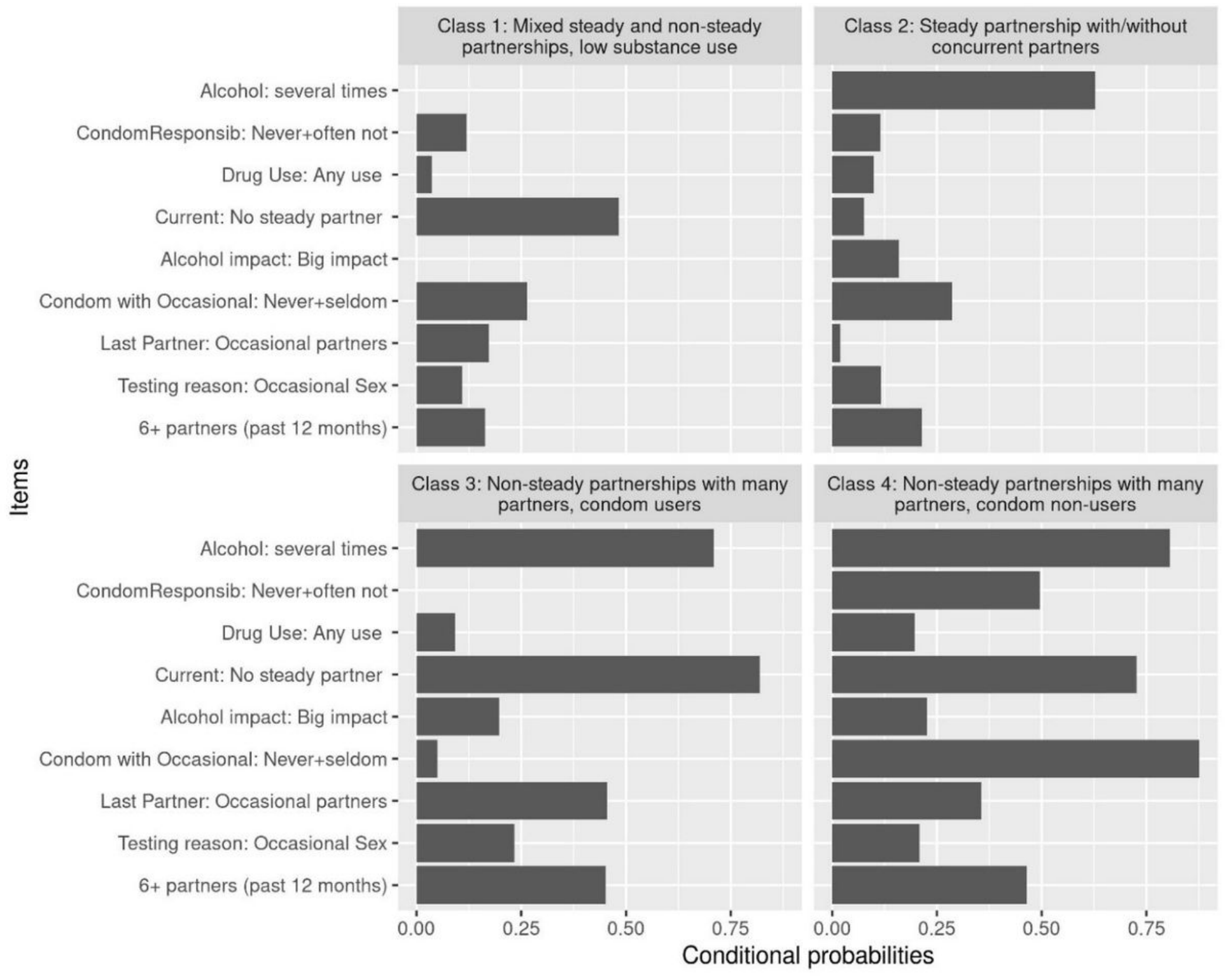

\section{Figure 1}

Latent class conditional probabilities for men $(\mathrm{N}=1,436)$ 


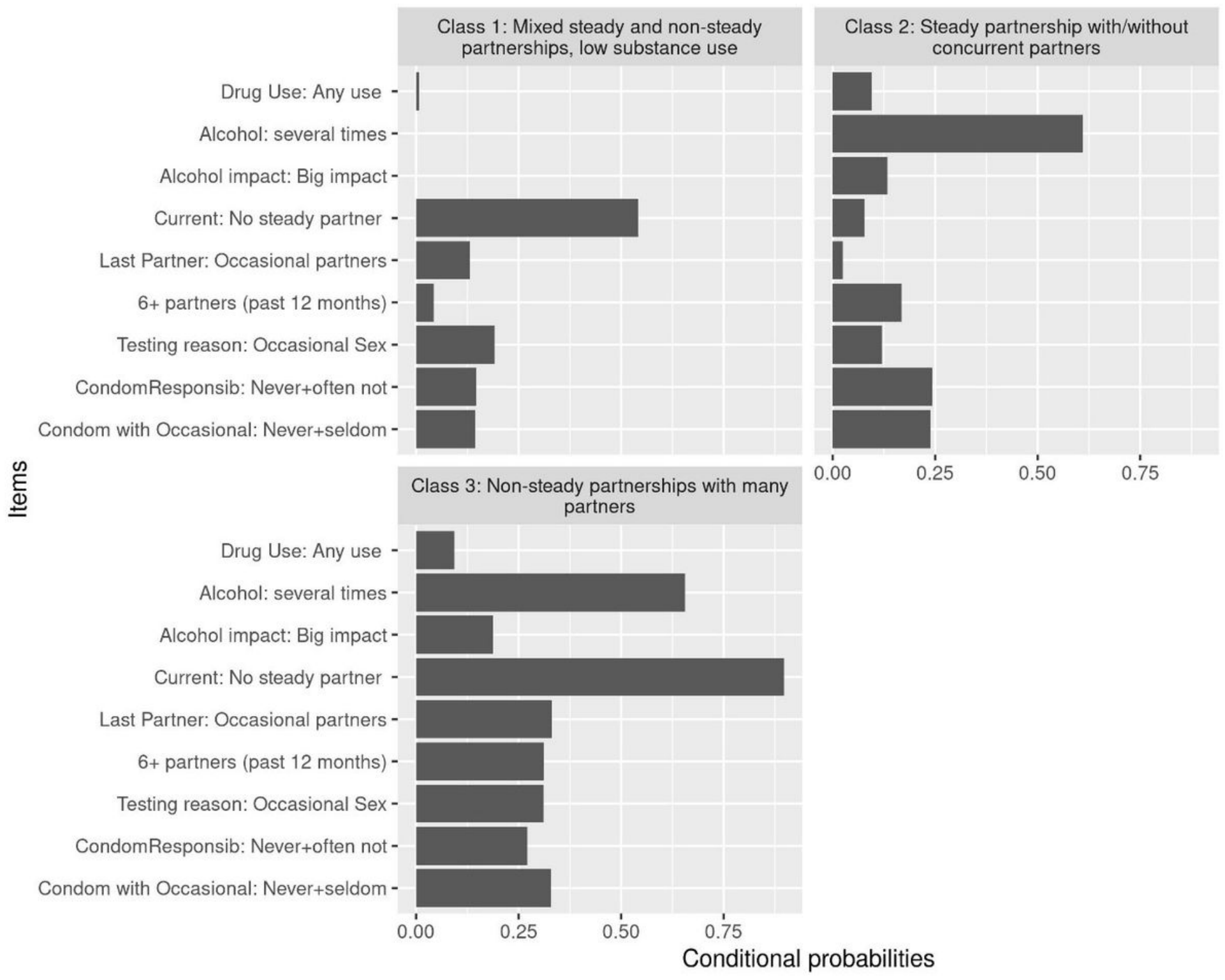

Figure 2

Latent class conditional probabilities for women $(\mathrm{N}=1,378)$ 


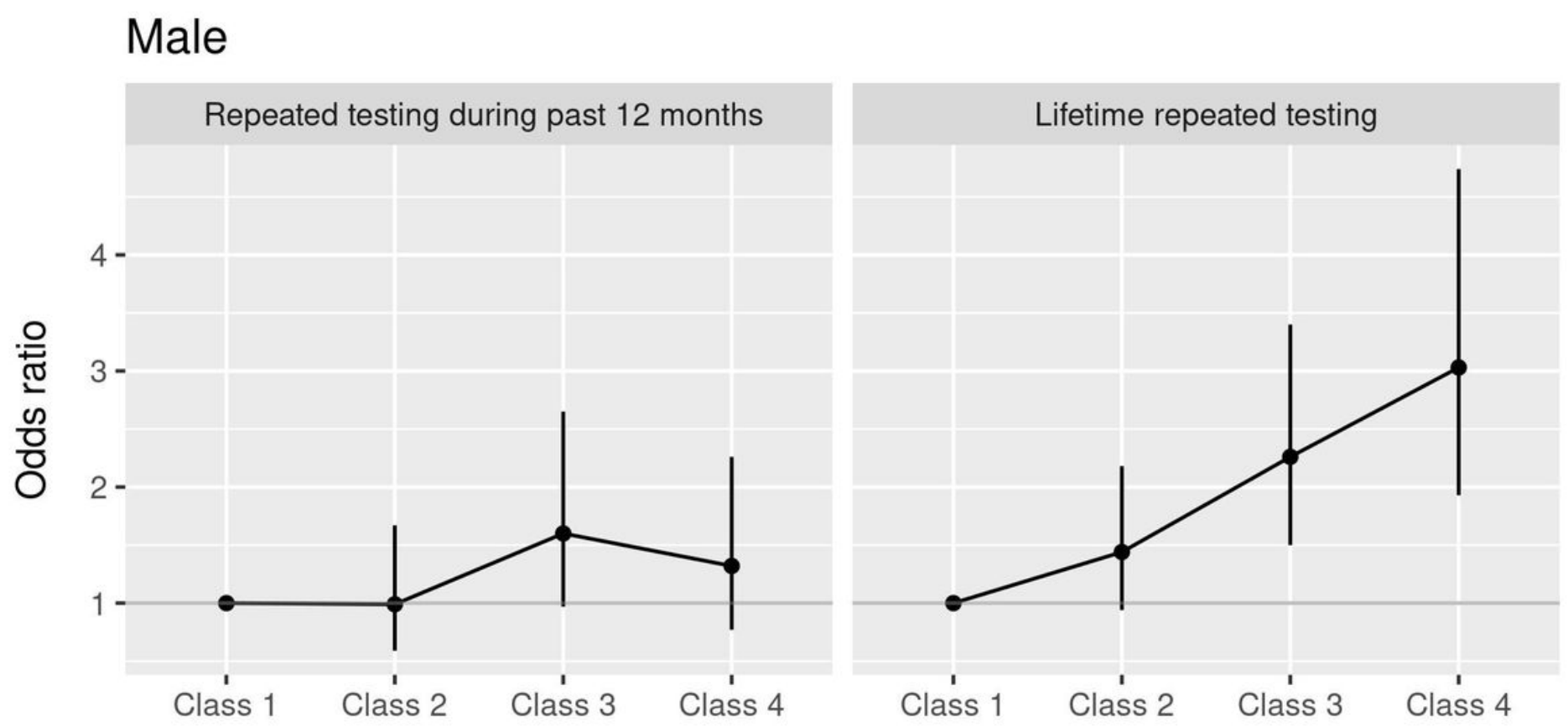

Female

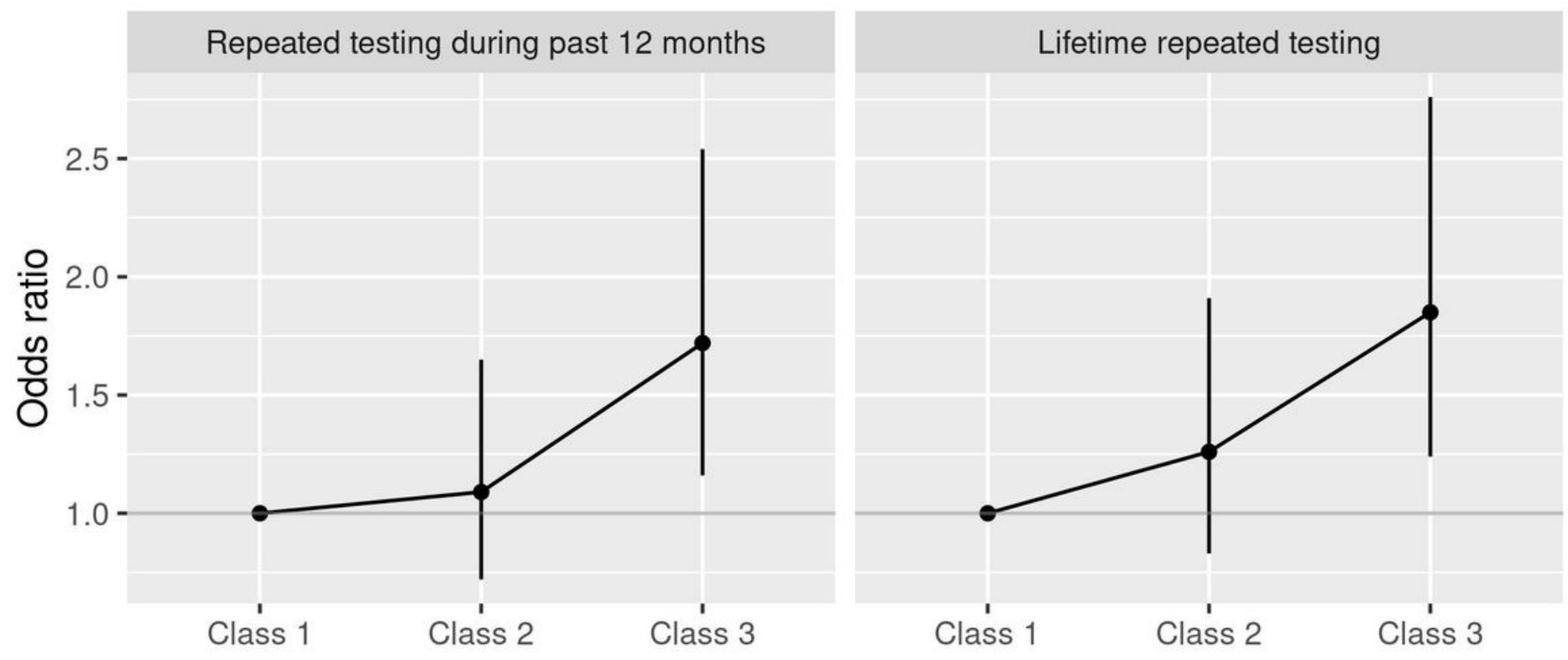

Figure 3

Association between latent class membership and repeated testing by sex, adjusted for age groups 


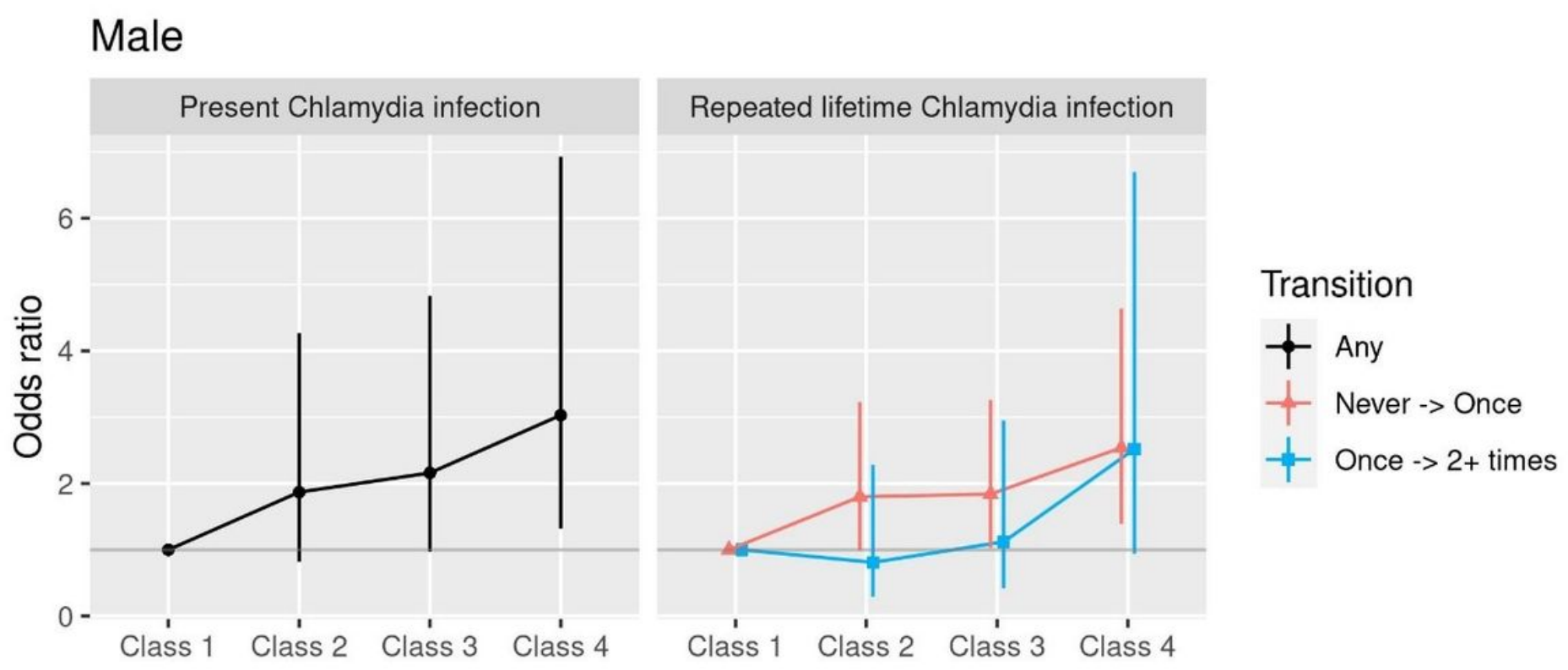

\section{Female}
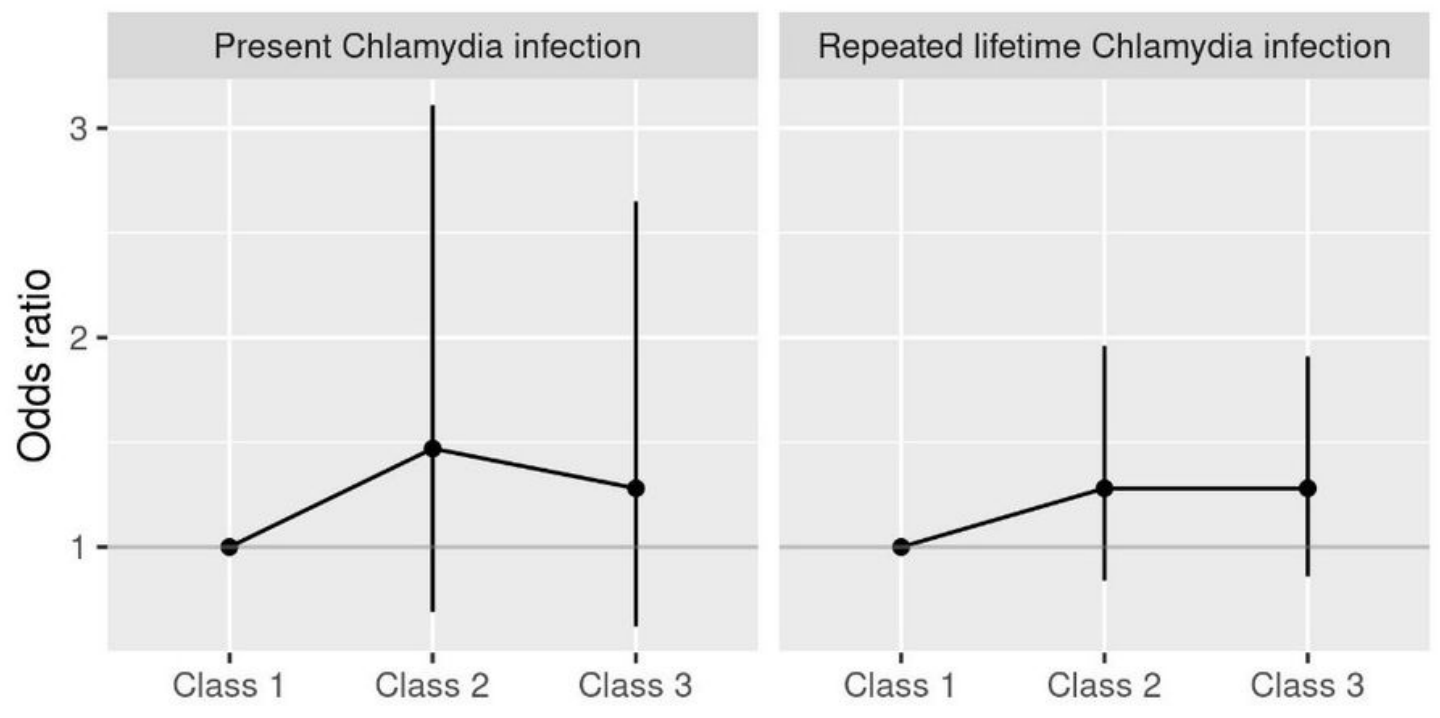

\section{Figure 4}

Association between latent class membership and lifetime chlamydia infection by sex, adjusted for age groups

\section{Supplementary Files}

This is a list of supplementary files associated with this preprint. Click to download.

- OnlineSupplementLatentClassAnalysisVelickosubmitted.docx 